\title{
Non Surgical Management of Large Periapical Lesions of Endodontic Origin: A Case Series
}

\author{
Gupta $\mathrm{A}^{1}$, Duhan $\mathrm{J}^{2}$, Hans $\mathbf{S}^{3}$, Goyal $\mathbf{V}^{4}$, Bala $\mathbf{S}^{5}$
}

\begin{abstract}
The success of root canal treatment is based on total elimination of root canal content, thorough cleaning, shaping and obturation of root canal system. Calcium hydroxide is recommended as intra-canal medicament because of its antibacterial properties, tissue dissolving ability, inhibition of tooth resorption and indication of tissue repair by hard tissue formation. The present case series highlights the use of calcium hydroxide as an inter appointment endodontic dressing for management of large periapical radiolucency and periodically reviewed. Thus the non surgical healing of large periapical lesions provided favourable clinical and radiographic response.
\end{abstract}

Keywords: Periapica 1 Lesion, Non Surgical Endodontic Therapy, Calcium Hydroxide

${ }^{1} \mathrm{PG}$ Demonstrator

Department of Endodontics

PGIDS, Rohtak, Haryana (INDIA)

${ }^{2}$ Professor

Department of Endodontics

PGIDS, Rohtak, Haryana (INDIA)

${ }^{3}$ Assistant Professor

Department of Periodontics

Choudhary Devi Lal Dental College, Sirsa,

Haryana (INDIA)

${ }^{4} \mathrm{PG}$ Demonstrator

Department of Orthodontics

PGIDS, Rohtak, Haryana (INDIA)

${ }^{5}$ Senior Professor \& Head

Department of Dental Materials

PGIDS, Rohtak (INDIA)

\section{Contact Autbor}

Dr. Alpa Gupta

alpagupta2008@gmail.com

J Oral Health Comm Dent 2014;8(3)172-175

\section{INTRODUCTION}

7 eriapical lesions of endodontic

$\int$ origin are mostly produced by an inflammatory response at the root apices of teeth with nonvital pulps. It is caused by imbalance between microbial factors and host defences at the interface between infected radicular pulp and periodontal ligament those results in local inflammation, resorption of hard tissues, destruction of other periapical tissues (1, 2). Most periradicular lesions, almost greater than $90 \%$ can be categorized as dental granulomas, radicular cysts or abscesses (3). Periapical lesions cannot be differentially diagnosed into cystic and noncystic lesions based on the radiographic features (1). The incidence of apical cysts amongst periapical lesions varies from $6 \%$ to $55 \%$ (4). The definitive diagnosis of a periapical cyst can be made only by a histological examination. Various studies have reported a success rate of up to $85 \%$ after endodontic treatment of teeth with periapical lesions $(5,6)$. A high percentage of $94.4 \%$ of complete and partial healing of periapical lesions following nonsurgical endodontic therapy has also been reported (7). All inflammatory periapical lesions should be initially treated with conservative nonsurgical procedures (4). Numerous non-surgical methods have been proposed to treat periapical lesions (8-14). Two techniques named decompression technique $(10,15)$ and aspiration-irrigation technique (9) aid in decreasing the hydrostatic pressure resulting in shrinkage of the lesion. At the same time the more conservative non-surgical approach that can be treated by intracanal medicaments can't be ignored. This article suggests that surgical removal of periapical lesion of pulpal origin is not mandatory, and that, irrespective of the size of the lesion, every effort should be made to treat such lesions by conservative means.

\section{CASE REPORT}

\section{Case 1}

A healthy 27-year-old woman was referred to the department of conservative and endodontics to verify a possible dental cause for a skin lesion. 


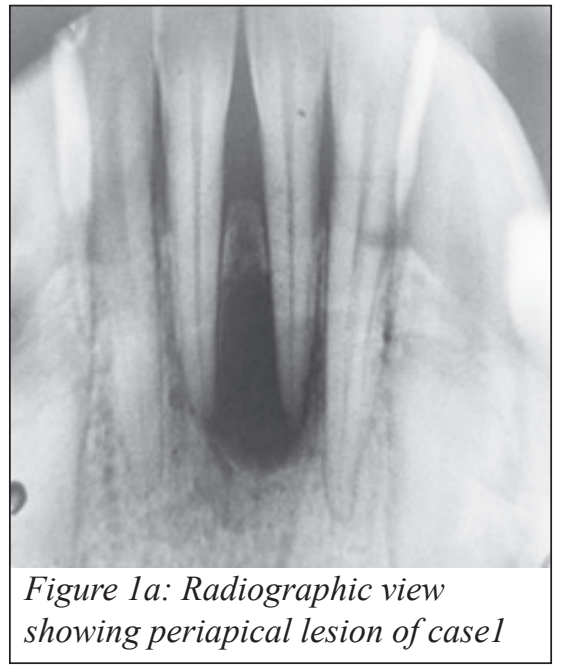

During history taking, the patient disclosed that she had been suffering from a cutaneous lesion present in the centre of chin area from past one year. Patient also gave history of trauma of 10-12 years back in lower front teeth. Clinical examination revealed no carious lesion present in teeth 41 and 31. Radiographic examination revealed large periapical radiolucency with respect to 41 and 31(Fig1a). With the help of vitality tests all the teeth were confirmed non vital. After local anaesthesia and rubber dam placement, root canal treatment was initiated with pulp chamber access and biomechanical preparation of the root canals. Irrigation during

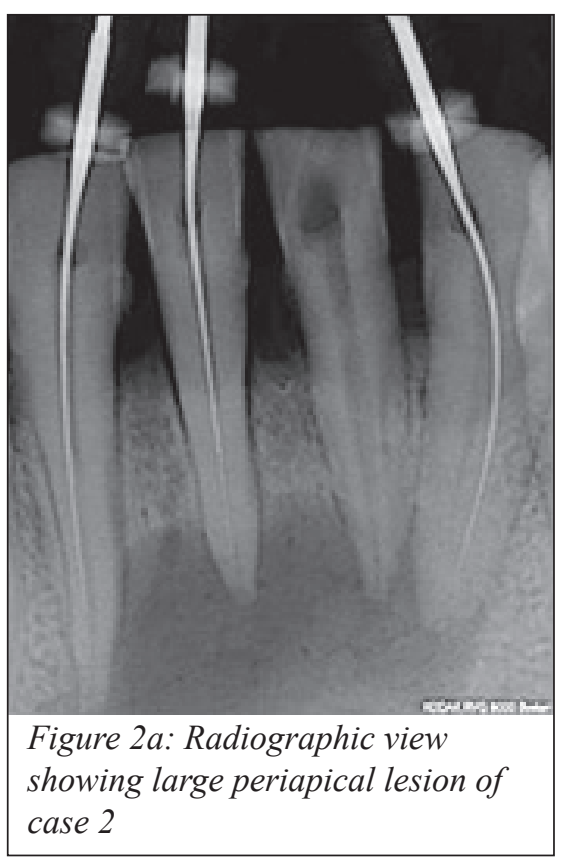

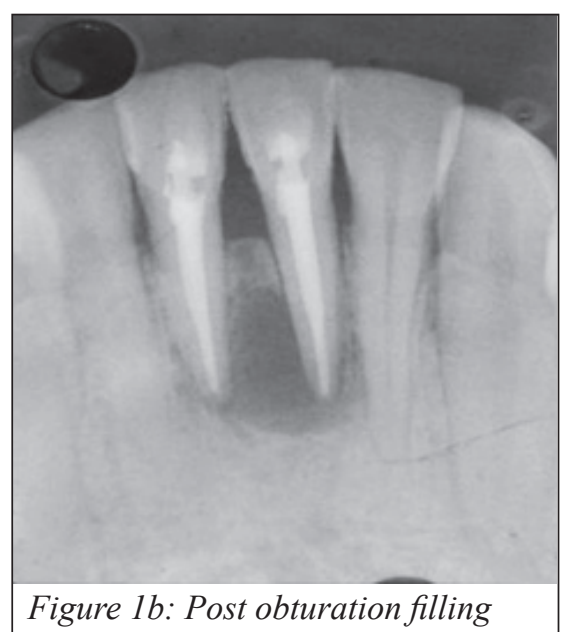

instrumentation was carried out with $3 \%$ sodium hypochlorite and final irrigation with EDTA. Paste of calcium hydroxide was used as the intracanal medicament. After 1 week, the canals were found to be dry. The canal filling was performed 2 weeks after the initial appointment (Fig1b). At the 1 year recall, healing of the extraoral sinus had occurred. Radiographic examination showed major reduction in size of periapical lesion (Fig1c).

\section{Case 2}

A healthy 30-year-old woman was referred to the department of Conservative and Endodontics to verify a possible dental cause for a skin lesion. This case was very similar to case one

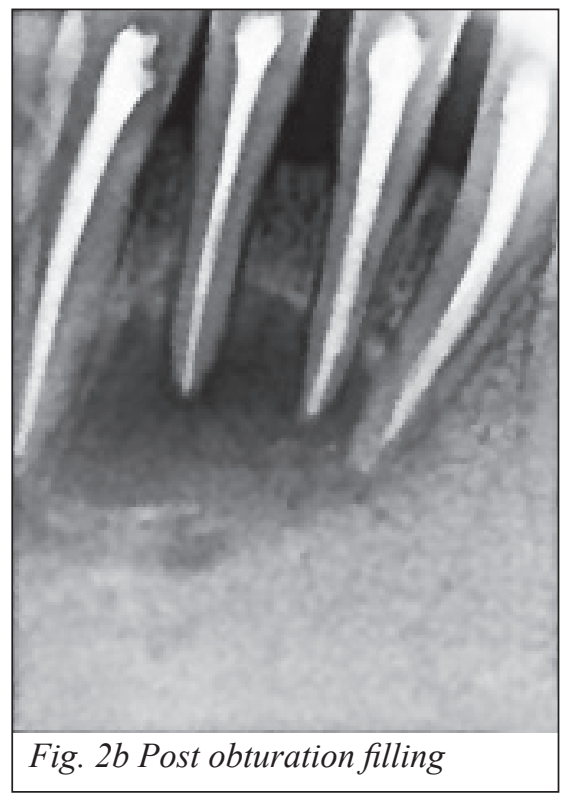

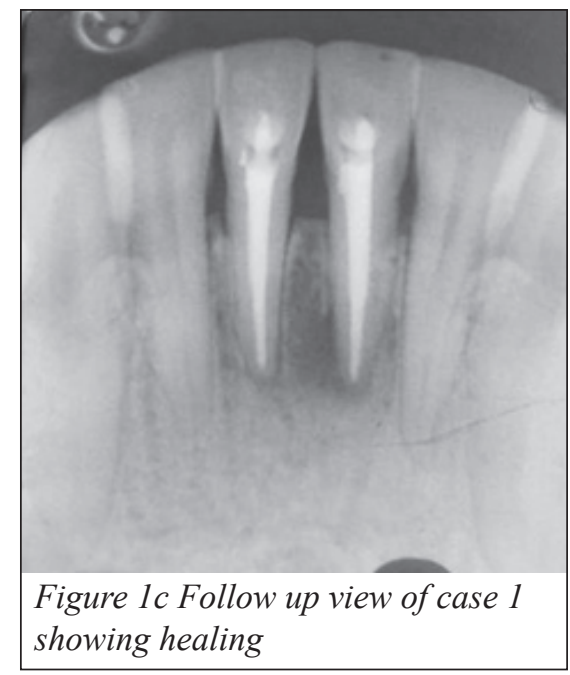

in which patient gave history of cutaneous lesion present in the centre of chin area from past 8 months. Patient also gave history of trauma of 10 years back in lower front teeth. Clinical examination revealed no carious lesion present in teeth 41, 42, 31, 32. Radiographic examination revealed large periapical radiolucency with respect to $41,42,31$, 32 (Fig. 2a). With the help of vitality tests all the teeth were confirmed non vital. The intraoral opening was traced with the help of gutta- percha point to localise the involved teeth. Again the root canal therapy along with irrigation was performed. Calcium hydroxide paste was used as the intra-

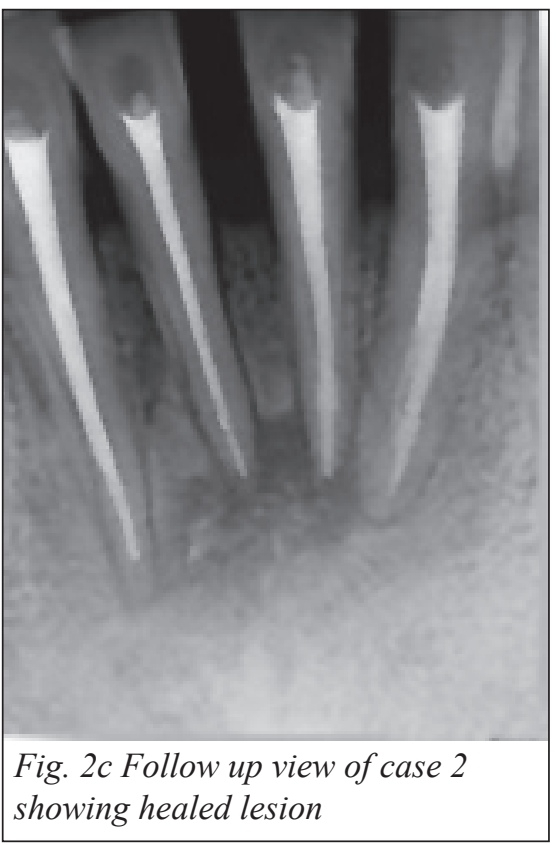




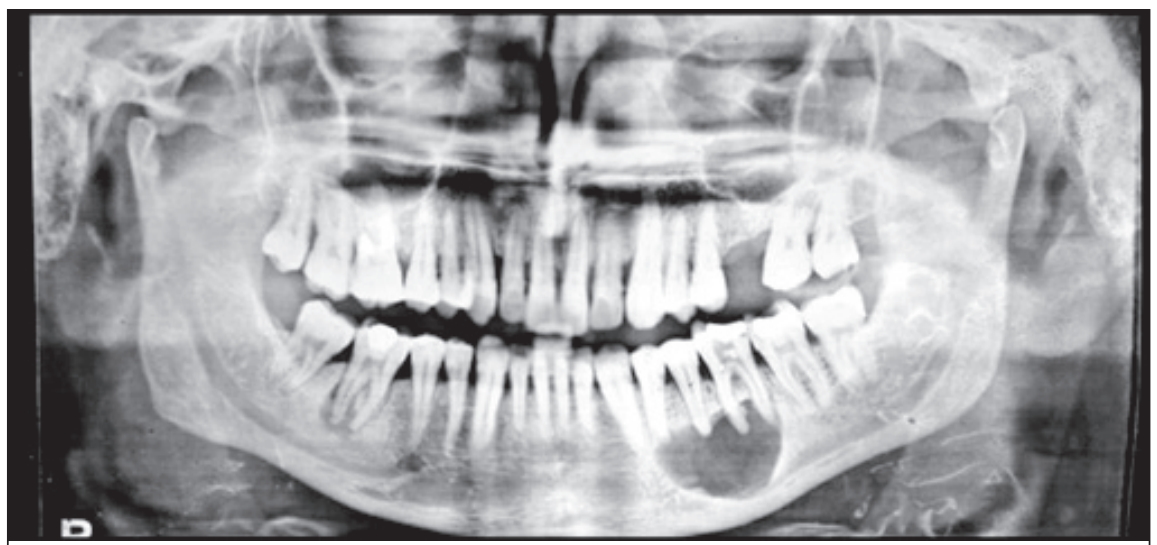

Fig. 3a O.PA.G view showing large periapical lesion of case 3

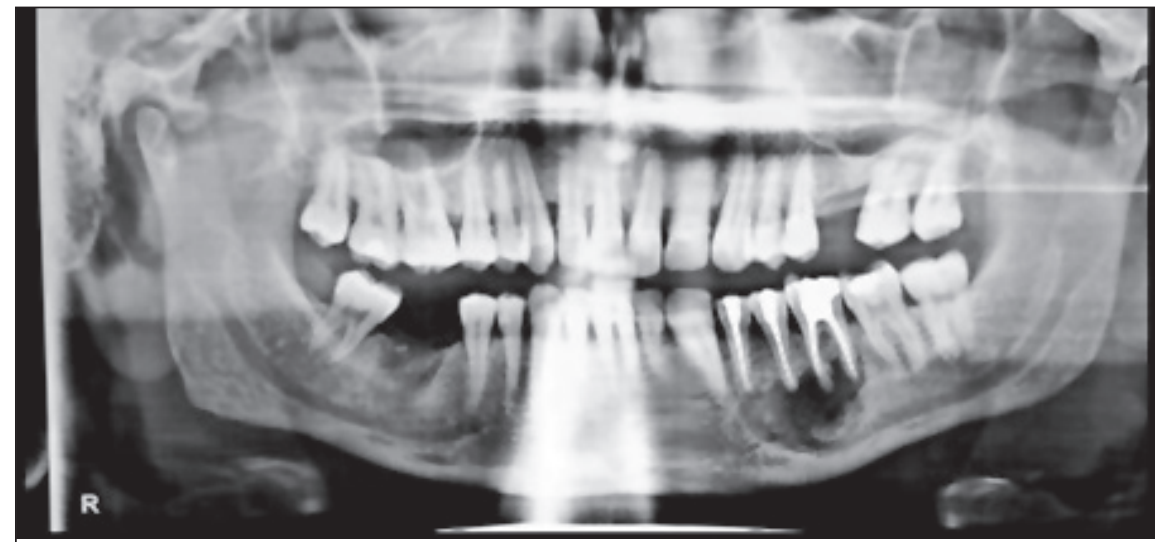

Fig. $3 b$ Post obturation filling

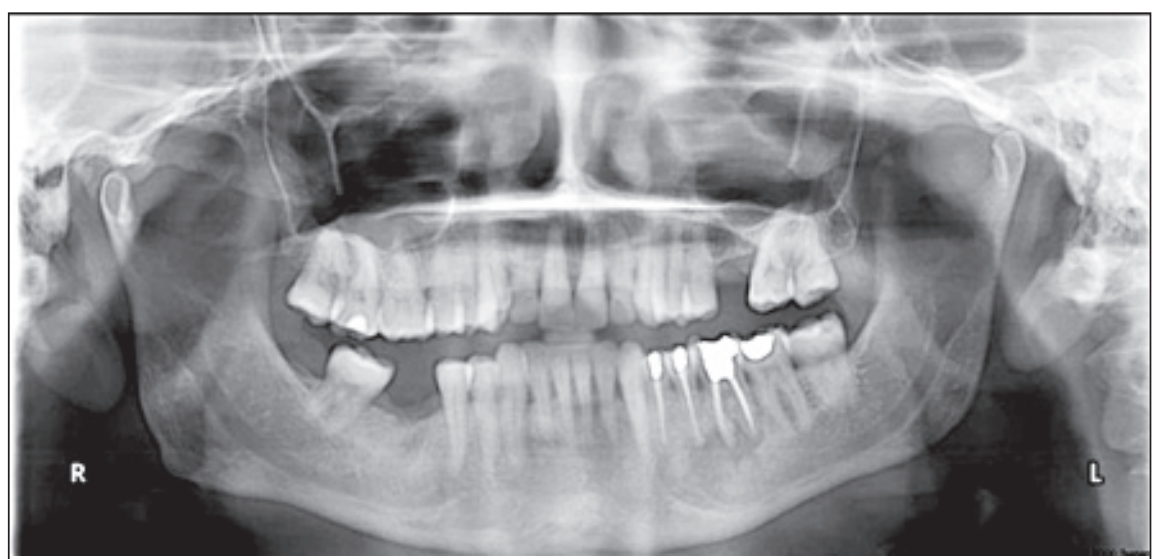

Fig. 3c Follow up view of case 3 showing healing

canal medicament. After 1 week, the canals were found to be dry. The canal filling was performed 2 weeks after the initial appointment. At the 4 months recall, healing of the extraoral sinus had occurred (Fig. 2b). 18 months radiographic follow up showed significant healing of periapical tissue (Fig. 2c).

\section{Case 3}

A healthy 25-year-old man was referred to the department of Conservative and Endodontics for treatment of right sided posterior teeth. Clinical examination showed a large temporary restoration with 36 . The radiographic
(O.P.G) (Fig. 3a) examination revealed pulp necrosis in tooth 36 and large periapical radiolucency around 34,35 and 36. All the involved teeth were non- sensitive to percussion, thermal and electric pulp tests. The root canal treatment was performed in various sessions and the clinical management was conducted as in case 1(Fig. 3b). A 18 months follow-up showed that the periapical tissues had healed (Fig. 3c).

\section{DISCUSSION}

Surgical treatment of all periapical pathologies is not always necessary since they may respond satisfactorily to the adequate endodontic treatment. A nonsurgical approach should always be adopted before resorting to surgery. Patients also are psychologically more anxious about surgical treatment than a non-surgical one. Also one needs to be aware of the risks and complications associated with medically compromised patient during surgical procedures.

So, all inflammatory periapical lesions should be initially treated with conservative nonsurgical procedures (4). Various non-surgical methods have been used to treat periapical lesions (8-13). Toller (14) proposed that the growth of the cyst may be attributable to the increased hydrostatic pressure of the confined fluid, which causes additional osteoclastic activity. The decompression technique $(10,15)$ and aspiration- irrigation technique (9) aid in decreasing the hydrostatic pressure resulting in shrinkage of the lesion. The decompression technique involves placement of tubing to maintain drainage (15). However, several disadvantages such as inflammation of alveolar mucosa, persistence of a surgical defect at the site, development of acute or chronic infection of the lesion, submergence of the tube and patient cooperation limit the use of this technique (16).

The aspiration- irrigation technique involves aspirating the fluid using a wide gauge needle attached to a syringe. The 
needle penetrates the lesion through the buccal mucosa, creating a buccal wound, and exits through the palatal mucosa creating a palatal wound that later act as a pathway for the escape of the irrigant. A disadvantage of this technique is the creation of the buccal and palatal wounds, which result in inflammation of the alveolar mucosa and cause discomfort (9).

Calcium hydroxide nowadays is widely used as an intracanal endodontic material, due to its high alkalinity (17) tissue dissolving effect, causes induction of repair by hard tissue formation and bactericidal effect $(18,19)$. Its antibacterial actions is due to its effect on bacterial cytoplasmic membranes, protein denaturation, damage to DNA, carbon dioxide absorption, its action on lipopolysaccharides and its hygroscopic action. In the presence of large periapical lesions such as in our three cases placement of intracanal calcium hydroxide would have a direct effect on inflamed tissue and epithelial cystic linings and in this manner would favour periapical healing and encourage osseous repair (17). Significant bone formation was seen at the periapical region on periodic check up visits. Thus non surgical healing of the multiple periapical lesions provided favourable clinical and radiographic response. Here, conventional endodontic therapy in combination with calcium hydroxide as an intracanal medicament contributed effectively in healing of periapical lesions. But, it would be necessary to observe and monitor the periapical lesions over a period of time following the non-surgical approach before the surgery is contemplated. In general, non surgical treatment or retreatment will be the preferred choice because it seems to provide the most benefit with the lowest risk. Surgical treatment is indicated only when nonsurgical treatment or retreatment is impractical or unlikely to provide the desired outcome. It is now believed that the activated macrophages in the periapical lesion are the reason for delayed healing of the lesions in the absence of bacterial antigens. The futuristic view of treating the periapical lesions include placement of biodegradable local sustained drug delivery points into the lesion before obturating the tooth to deactivate the macrophages and enhancing the faster healing of the lesions (12).

\section{CONCLUSION}

In this case series nonsurgical endodontic therapy proved successful in promoting the healing of periapical lesions. Irrespective of the size of the lesion every attempt should be made to treat the periapical lesions with non surgical endodontic therapy.

\section{REFERENCES}

1. Nair PN. Apical periodontitis: a dynamic encounter between root canal infection and host response. Periodontol 2000 1997;13:121-48.

2. Nair PN. Pathogenesis of apical periodontitis and the cause of endodontic failures. Crit Rev Oral Biol Med 2004;15: 348-81.

3. Bhaskar SN. Periapical lesion - types, incidence and clinical features. Oral Surg, Oral Med Oral Pathol 1966;21: 657-71.

4. Lin LM, Huang GT, Rosenberg PA. Proliferation of epithelial cell rests, formation of apical cysts, and regression of apical cysts after periapical wound healing. J Endod 2007;33:908-16.

5. Sjogren U, Hagglund Sundqvist G, Wing K. Factors affecting the long term results of endodontic treatment. $J$ Endod 1990;16:31-37.

6. Caliskan MK, Sen $\mathrm{BH}$, Endodontic treatment of teeth with apical periodontitis using calcium hydroxide: a long term study. Endod Dent Traumatol 1996;12: 215-21.

7. Murphy WK, Kaugars GE, Collet WK, Dodds RN. Healing of periapical radiolucencies after nonsurgical endodontic therapy. Oral Surg Oral Med Oral Pathol 1991;71:620-24.

8. Shah N. Nonsurgical management of periapical lesions: a prospective study. Oral Surg Oral Med Oral Pathol 1988;66: 365-71.

9. Hoen MM, LaBounty GL, Strittmatter EJ. Conservative treatment of persistent periradicular lesions using aspiration and irrigation. J Endod 1990;16:182-86.

10. Loushine RJ, Weller RN, Bellizzi R, Kulild JC. A 2-day decompression: a case report of a maxillary first molar. $J$ Endod 1991;17: 85-87.

11. Caliskan MK. Prognosis of large cyst-like periapical lesions following nonsurgical root canal treatment: a clinical review. Int Endod J 2004;37:408-16.

12. Er K, Kustarci A, Orzan U, Tasdemir T. Nonsurgical endodontic treatment of dens invaginatus in a mandibular premolar with large periradicular lesion: a case report. $J$ Endod 2007;33:322-24.

13. Metzger Z, Huber R, Slavescu D, Dragomirescu D, Tobis I, Better H. Healing kinetics of periapical lesions enhanced by the Apexum procedure. $J$ Endod 2009;35:153-59.

14. Toller PA. Newer concepts of odontogenic cysts. Int J Oral Surg 1972;1:3-16.

15. Martin SA. Conventional endodontic therapy of upper central incisor combined with cyst decompression: a case report. $J$ Endod 2007;33:753-57.

16. Caliskan MK, Turkun M. Periapical repair and apical closure of a pulpless tooth using calcium hydroxide. Oral Surg Oral Med Oral Pathol 1997;84:683-87.

17. Tronstad L, Andreasen JO, Hasselgren G, Kristerson L, Riis I. pH changes in dental tissue after root canal filling with calcium hydroxide. J Endod 1981;7:17-21.

18. Siqueira JF, Lopes HP. Mechanisms of antibacterial activity of calcium hydroxide: a critical review. Int Endod J 1999;32: 361-69.

19. Sjogren U, Figdor D, Spangberg L, Sundqvist G. The antimicrobial effect of calcium hydroxide as a short term intracanal dressing. Int Endod J 1991;24: 119-25. 